Journal of Humanities, Social and Management Sciences (JHSMS)

eISSN: 2788-4791 (online)

https:// doi.org/10.47264/idea.jhsms/2.1.2

Vol. 2, No. 1 (January-June 2021), 10-23

https:// www.ideapublishers.org/index.php/jhsms

Research Article

\title{
Professional skills of speech therapist in special education centres of Punjab, Pakistan
}

\author{
Aqsa Mumtaz ${ }^{1}$ Bareera Saeed $^{* 1} \mid$ Muhammad Aurangzeb Khan ${ }^{2}$
}

1. Department of Health Professional Technologies, Faculty of Allied Health Sciences, The University of Lahore, Lahore, Pakistan.

2. Department of Psychology, Faculty of Social Sciences, University of Karachi, Karachi, Pakistan.

3. Department of Social Work, Faculty of Social Sciences, Women University Swabi, Swabi, Pakistan.

*Correspondence Emails: bareera.saeed@ dhpt.uol.edu.pk | bareerasaeedwarraich@ gmail.com

Published: August 6, 2021

\begin{abstract}
Speech-Language Pathologists (SLPs) are responsible for evaluating and treating speech language impairments through professional knowledge and skills, but they also provide other resources such as evaluating and treating swallowing issues, impaired memory, and hearing issues. The present study is about the factors affecting the professional skills of speech therapists in special education centres of Punjab. A cross-sectional research design was used. A total sample of 75 speech therapists was drawn through purposive sampling technique in special educational centres of Punjab included districts of Lahore, Mandibahudin, Sahiwal, Okara, and Shekhupura. There were $68(90.7 \%)$ participants between the ages of 20 to 30. There were 61 $(81.3 \%)$ male participants and $14(18.7 \%)$ female participants in the study. Results shows that majority of female participants $(39.3 \%)$ strongly agreed that speech therapist are not sufficient in special educations centres and its caused work burnout among $49.5 \%$ female participants but there is no gender association value of $p>0.001 .50 .8 \%$ females participants agreed training and latest assessment tools are required for desired outcomes in therapeutic sessions. This research concluded that failure to ensure efficient technical skills of speech and language pathologist in special education centres has resulted in a slew of permanent, deadly effects for SLP.
\end{abstract}

Keywords: Speech Language Pathologist (SLP), professional skills, knowledge, workload, assessment tools, special education centres.

How to Cite: Mumtaz, A., Saeed, B. \& Khan, M. A. (2021). Professional skills of speech therapist in special education centres of Punjab, Pakistan. Journal of Humanities, Social and Management Sciences (JHSMS), 2(1), 10-23. https://doi.org/10.47264/idea.jhsms/2.1.2

Publisher's Note: IDEA PUBLISHERS (IDEA Journals Group) stands neutral regarding jurisdictional claims in the published maps and institutional affiliations.

Copyright: (C) 2021 The Author(s), published by IDEA PUBLISHERS (IDEA Journals Group)

This is an Open Access article published under the Creative Commons Attribution-Non Commercial 4.0 International License (http://creativecommons.org/licenses/by-nc/4.0/) 


\section{Introduction}

Speech Language Pathologists (SLPs) uses a variety of techniques, including providing areas for speech language pathology and clinical practice. SLPs also work with students who have serious communication disabilities, such as language, speech impairments (speech sounds), fluency (speech speed), voice/resonance, and swallowing problems. SLPs work with patients to develop their verbal and written speech, as well as their auditory and reading comprehension (Glover et al., 2015). SLPs specialize in oral and household swallowing disorders, as well as swallowing recovery, and provide services to slow learners and other students who are at risk of failing in school. They assist the patients after extensive consultations. SLPs concentrate on family, academic, mental, social, and vocational needs that affect educational objectives, and they may play a variety of roles depending on their language experience. They also assist students with disabilities in the care of the verbal and nonverbal foundations of course learning (Ch et al., 2021).

SLPs are self-employed professionals whose goal is to provide speech and language services. They are not supervised, regulated, or tracked by any other health professional (Hill, 2017). SLPs can also work with other peer experts to reach a decision about counselling mythologies or outcomes. Their professional judgments reflects their abilities and knowledge in their respective fields (Douglas et al., 2019). The term "clinician" is the most widely used term to describe a specialist's approach to treating patients with speech, language, and related issues. This was preferred over "pathologist", which denotes a research that does not include sickness or disease, or "therapist", which denotes a focus on recovery (Hegarty et al., 2021). The term clinician may conjure up images of work in medical settings, such as at the hospital bedside or in health clinics, as well as a primary concern for the conditions and disorders that may present. Above all, it sends the message that the expert in question is analytical and uses a research, problem-solving approach to people-client observation, assessment, and management (Parveen, 2015).

Varieties of interventions are available to therapists, including articulation treatments, intervention, swallowing, and oral therapies. Collaboration, therapy, prevention and wellness, screening, evaluation, care, modalities, technology, and instrumentation, and population and systems 8 are the eight fields of speech-language pathology service delivery (Law et al., 2017). They deal with goals one at a time, in groups, or in big groups such as classrooms. A Speech and Language Therapist (SLT) may work in a hospital or health centre clinic, but there are other places where they can contact clients. SLPs can contact their place of residence, such as a family home or a care facility, or the place where they go during the day, such as a day centre or a school. SLPs can also operate in other environments, such as resource centres that provide users with an augmentative communication framework. The speech therapist will also discuss re-educational methods for the deglutition and the phoning recovery, with the aim of instilling a calm and the optimistic attitude toward the treatment and the post-operative rehabilitation (Ch et al., 2021).

Many people are familiar with speech therapists in clinics and hospitals, but have little idea what a speech therapist does in a special education centre setting because there is a large gap in factors affecting clinical skills of speech and language therapists in special education centres (Mngo \& Mngo, 2018). There are several factors that influence the professional skills of speech and language therapists in special education centres in Pakistan; the current study focuses on 
factors such as availability, professional experience, factors influencing professional skills, workload, and evaluation tools. Failure to maintain an appropriate technical skill of speech therapists in special education centres has resulted in a slew of permanent and fatal effects for SLPs (Brandel, 2020).

Several factors influence SLPs professional skills, including teamwork and contact with coworkers, administrative support, provision and condition, workload and SLP preparation and awareness. Other factors, such as years of experience, styles, and strength of professional experience, as well as continuing education, influence the degree to which individuals provide unique EI services in a comfortable and competent manner (Campbell \& Douglas, 2017). In the technical fields, there is very little literature on knowledge, type, or strength of case load, and their ability to perform special duties satisfactorily. However, in a scientific sense, some expert's support the connection because it is defined as relaxation and the procedure on palms has been investigated (Shafaroodi et al., 2017).

SLPs do not have laptop experience, and their field of expertise has communication issues. Older and younger generations of SLPs, on the other hand, must devise strategies to adapt IT technologies to their care objectives (Anderson et al., 2015). Similarly, SLPs faces a variety of obstacles in their professional lives, including heavy workloads, erroneous time management, inconsistent client responses and attitudes, a lack of coordination with seniors, inadequate management support, and irregular job assignments. Several success metrics of speech therapists will be evaluated in this report, including clinical expertise, time management, workload, and patient engagement (Chu et al., 2019). The findings of this study will assist speech therapists in concentrating their efforts on high output success metrics.

Speech therapists assist young children in learning to communicate and people with speech difficulties in communicating effectively (Wilson et al., 2015). The aim of this study is to identify numerous factors that obstruct the implementation of therapy procedures, facilities, and technology in special education centres, and to determine how these skills can be efficiently applied in their speech strategies to achieve the desired results. This research will show us how to operate a speech centre efficiently by integrating core professional skills and achieving the desired outcome and patient satisfaction. Speech therapists operate in various rehabilitation centres and special education centres in Pakistan, and the ultimate goal of this study is to identify restricting factors in applying professional skills of SLP in a realistic setting.

\section{Literature review}

This section examines the literature on factors influencing speech therapists' professional skills in Pakistani special education centres. It will look at the following topics: overview of the definition of special education, types of learners with special needs, and factors affecting the use of speech and language therapists' professional skills in special education settings. According to Walsh (2018), it is common to believe that special education is the least important aspect of the general faculty device; however, this belief is wrong, as special education often necessitates more complex and complicated tasks than general education. Special education is designed to provide education to each student by taking into account special educational requirements. Style schooling includes students on a daily basis with trend/shared environments, while specialized education is focused on asset adjustment in a passive activation context, teaching methodological plans, and analytical exercises (Walsh, 2018). 
According to Short et al. (2016), more general variables found in different speech or language therapies can also contribute to positive outcomes. For example, in speech or language recovery study, the clinician's role is often underestimated or ignored, despite evidence that clinics are an important component of comparative field therapy. Strange factors can be compared to speech language pathology, particularly in relation to additional individuals. Many speech therapists have unique elements within the physician-user relationship regarding their treatment, specific to the length of the care plan, and the client's expectations of performance have an overall outcome (Short et al., 2016). The implicit clinical centre of experienced practitioners can help form these perspectives, but the goal is not always to capture these wellknown elements through speech and language action. The danger of overlooking common factors is examined, as is the efficacy of remediation. Ignoring these variables at first may not negate their impacts, and the results of the study can be muddled as a result. Second, by missing the significance of strange elements, we fail to recognize and use records that can help us optimize care outcomes (Luterman, 2021).

Davidson et al. (2015) discovered that language-impaired children and adolescents have trouble forming and sustaining positive social relationships, particularly relationships with their peers, on a daily basis. Speech pathologists must learn which facets of communication best facilitate peer engagement and, as a result, potentially strengthen peer relationships (Davidson et al., 2015). Speech pathologists' decisions that include both the pros and cons of the intervention will motivate them to communicate in a way that minimizes and eliminates major communication errors. Speech pathologists should adopt strategies to discourage the social discrimination of patients (Aguilar, 2021). Expert therapists who jog with children and particularly people who walk with children and adults who are experiencing anxiety believe that speech therapists might be trained through this speech wrapping assistant who performs without supervision. Some medical skills, mutual skills, and management skills were among them (Calle-Romero et al., 2017) Physicians who work with elderly people with neurological disabilities on a daily basis, on the other hand, were more cautious than those who were assisted by assistants who helped straighten them out (Zerbo et al., 2015).

According to Hamid et al. (2021), academic performance of speech affected children is going bad due to depression and anxiety. Speech counsellors must be trained the skills handle anxiety and depression and respect should be given to special children by all staff of any special institutions (Hamid et al., 2021). Pakistan initiated a program in 1980s to increase the number and quality of established education centres for both men and women. However, the continued lack of any sort of schooling for children who seek individual education denies the right to attend high school to an unexpected number of these young people (Roof, 2015). A study on beginner clinic staff was written by Volkmer et al. (2020). The goal students spoke English as a second language, which posed a significant barrier to their clinical practice. Several issues, such as communication, learning style, and professional conduct, were highlighted in this report, which could help professionals develop their skills in future (Volkmer et al., 2020). Noor and Raja (2019), compiled the constraints faced by SLPs during practice in schools about Speech-Language Pathology in Schools, which was published in an article by Allama Iqbal Open University Islamabad. Restricted parental dialogue and participation, large tasks, discouraging workers, and, last but not least, limited resources are the major issues (Noor \& Raja, 2019). Other limitations were identified in a study conducted by St. Bernard Elementary School in Ohio. Collaboration with colleagues and the demand for proof of clinical practice by higher authorities have so far been highlighted as limitations (Kadyamusuma, 2016). 
Special education in Pakistan is defined by national coverage, particularly in the areas of school education expectations, specific school curricula, and evaluation and innovation for teacher education packages in schools. Goals are indicated. In Punjab and Sindh, as well as Baluchistan and KPK, the Ministry of Education is responsible for the education of children with special educational needs. The Ministry of Women's Development, Social Welfare, and Special Education created this portfolio. In addition to evaluating Pakistan's individual educational needs, he urged the federal and provincial governments, as well as non-governmental organizations (NGOs), to collaborate on the training of special children and to ensure cooperation and cooperation in sports (Durrani \& Halai, 2018). Thompson (2019) in his study described the experiences of clinical professionals when fulfilling their roles as pathologists in higher education. This research can be used to help clinical practitioners better in the future, particularly at higher levels of education. Workload, false time management, inconsistent client response and behaviour, lack of coordination with seniors, inadequate management support, and irregular work assignments are the primary constraints. Aside from highlighting these issues, a few activities that are important for SLPs were listed. Self-realization, realization of roles as a clinical trainer, self-confidence, and realization of relationships with colleagues and patients are examples of these obligations (Shahin et al., 2015).

Weiss and Rohland (2015) assess practical application of ethical practices in clinical practices of phonetics and linguistics. It is needed to refresh and broaden their commitment and expertise to ethical coaching opportunities. The Powel Model of ethical practices is used to create Communication Coaching Program (CCP) based on six ethical constructs. Results of 4 year CCP programs revealed that communication programs should be customized or adopted according to individual needs in addition to being based on ethical standards. Workers behaviour and team's long-term strategy focuses and builds on a practical software program of creativity that directs and trains people for their responsibilities and allows us to reach goals. With that in mind, it appears to be a method for converting PD teachers into a tool for converting them to experts (Weiss \& Rohland, 2015). Lytton et al. (2019) in his latest work, "Problems and Issues in Education" writes that "during the strong economic domestic historical past, with the aid of a supportive mother and father, there is a need to beautify a child's overall modest academic overall success". This point can be expected from scholarly teaching performances in which the child is advised to make informed decisions about his teachers and experts who are interested in his mental skills, interests, and sports. Agers may have to deal with illiterate mania. Discover yourself by putting in the effort to walk the streets.

\section{Theatrical framework}

This study is based on a plan by the American Speech Language Hearing Association (ASHA). SLPs work for individuals, families and groups from a variety of language and cultural backgrounds. Services are provided based on the use of the best research evidence, using expert clinical judgments, and taking into account customer preferences and values. Speech therapists deal with common and unusual communication problems and swallowing problems. Speech therapists also offer their services to people who want to improve their accent or communication skills. Speech therapists play the role of supervision as well as are responsible for professional growth and development of its colleague's. Therefore, clinical education is an important aspect for a speech therapist either to perform role of a supervisor or an administrator in a clinical setting. Skills and expertise needed for it are crucial for successful services delivery to patients, students or clinical fellows. 
Skills needed by speech therapists may be gained by practicing with seniors, participating in course workshops, self-study of filed relevant material. A speech therapist must clearly access the problem, understand and demonstrate the best practices and use alternative assessment procedures if needed, must be able to build an effective client-clinician relationship, apply the specific tools and techniques to clients being served, must be able to properly counsel the clients and demonstrate the results obtained after therapy. Speech therapist develop a treatment plan for patients using application of his knowledge, skills and expertise based of various intervention materials, procedures, evidence based techniques, data collected from client behaviours and performance and decide when to use extra resources for intervention (Swan et $a l ., 2018)$. Speech therapists also consider social relationships of patients to be modelled in a way that is fruitful for both the patient and society. Ethical Standards are also kept in mind to avoid any type of discrimination among patients (Boyle, 2015). This study focuses on the technical and clinical aspects of the skills of speech therapists.

\section{Research methodology}

This observational cross-sectional research was carried out in special educational centres in the Punjab districts of Lahore, Mandibahudin, Sahiwal, Okara, and Shekhupura. A total of 73 speech therapists were included in this study's sample. There are 68 (90.7\%) participants between the ages of 20-30, 6(8.0\%) participants between the ages of $31-40$ and $1(1.3 \%)$ participant between the ages of 41 and 50 . There are 61(81.3\%) male participants and 14 (18.7\%) female participants in the survey, which is a sufficient sample size for the subject. Purposive sampling was used to select a sample from the population. The instrument was created using a literature review and expert opinion on the topic.

The setting of this research setting was "Lahore, Mandibahudin, Sahiwal, Okara and Shekhupura" where the factors affecting the professional skills of Speech and language pathologists in special education centres was studied. Study population for this research work was the all speech therapists of Lahore, Mandibahudin, Sahiwal, Okara and Shekhupura. The sample size of this research study was consisting of 73 speech therapists to evaluate the factors affecting the professional skills of speech and language pathologists in special centres of district Lahore, Mandibahudin, Sahiwal, Okara and Shekhupura.

A data collection instrument was developed with the help of expert opinion and available literature. Content analysis was done to find out reliability and validity of the questionnaire. After that, this questionnaire applied for data collection from speech language therapist working special education centres. Professional skills of SLPs are measured by getting information about number of tests instruments available in special education centres. A structured close-ended questionnaire based on twenty-nine items was used to measure the workload on SLPs in special education centres, professional skills of SLPs, satisfaction of assessment tools used by Speech therapists. Five point LIKERT scale was used in developing questionnaire. Responses were collected in "Strongly Disagree", "Disagree", "Neutral", "Agree" and "Strongly Agree" options.

Data was collected through survey method. After collecting the data, it was entered into Statistical Packages for Social Sciences (SPSS) version 23 and results were maintained through frequency and percentage method. Descriptive statistic was used for the description of demographic variables of the therapist. Chi Square test was used to see the association of the 
professional skills between the male and female (Speech Language Pathologist). SLP working in Special Education Centre of having minimum 1 year experience was included. Pathologists having minimum qualification diploma in speech language pathologist were not included. Pathologist currently working in special education centres were included. SLP having age of 22 or above were included. Pathologists of district Lahore, Mandibahudin, Sahiwal, Okara and Shekhupura were included. SLP who were on leave were not included.

\section{Results and discussion}

The results deal with data analysis. Frequency and percentages were used to evaluate the factors. Table-1 indicates background feature of the speech therapists considering age, gender, qualification, work experience, and work setting. There are 68(90.7\%) participants are 20-30 years old, 6(8.0\%) participants are 31-40 years old while 1(1.3\%) participants are 41-50 years old. There are $61(81.3 \%)$ male participants and 14(18.7\%) female participants sample size as per topic need participate in survey. The qualification of the participants was BS 10(13.3\%), MS 33(44.0\%), Diploma holders 17(22.7\%) and other 15(20.0\%). The work experience of the participants were 1 to 3 years 51(68.0\%), 2 to 5 years 2(2.7\%), 3 to 6 years $17(22.7 \%)$ and more than 6 years $5(6.7 \%)$. The work setting of the participants were special education centre 26(34.7\%), medical centre 39(52.0\%) and other (13.3\%). The number of conferences attended was 0-20 times was $72(96.0 \%), 21-40$ times was $2(2.7 \%)$ and $41-60$ times was $1(1.3 \%)$. The number of workshops attended 0-20 times was 74(98.7\%) and 1(1.3\%) was 81-100 times. The number of seminar attended 0-20 times was 74(98.7\%) and 1(1.3\%) was 81-100 times.

Table-1: Demographic characteristics of sample

\begin{tabular}{llr}
\hline Background & Variables & $\mathrm{N}=75(\%)$ \\
\hline Age & $20-30$ Years & $68(90.7)$ \\
& $31-40$ Years & $6(8.0)$ \\
Gender & $41-50$ Years & $1(1.3)$ \\
& Male & $61(81.3)$ \\
Qualification & Female & $14(18.7)$ \\
& BS & $10(13.3)$ \\
& MS & $33(44.0)$ \\
Work Experience & Diploma & $17(22.7)$ \\
& Other & $15(20.0)$ \\
& 1 to 3 years & $51(68.0)$ \\
Work Setting & 2 to 5 years & $2(2.7)$ \\
& 3 to 6 years & $17(22.7)$ \\
No. of Conferences attended & More than 6 years & $5(6.7)$ \\
& Special Education Centre & $26(34.7)$ \\
No. of Workshops attended & Medical Centre & $39(52.0)$ \\
& Other & $10(13.3)$ \\
No. of Seminar attended & $0-20$ Times & $72(96.0)$ \\
& $21-40$ Times & $2(2.7)$ \\
& $41-60$ Times & $1(1.3)$ \\
& $0-20$ Times & $74(98.7)$ \\
& 81-100 Times & $1(1.3)$ \\
& $0-20$ Times & $74(98.7)$ \\
& 81-100 Times & $1(1.3)$ \\
\hline
\end{tabular}


According to table-2 for the statement, "no of speech therapists are sufficient according to patients' ratio" results showed that majority of males (35.7\%) agreed with the statement while in females most participants (39.3\%) strongly agreed with P value 5.22. For the statement "due to the excessive workload sometimes it is frustrating to take that much sessions" results showed that a majority of males $(35.7 \%)$ and females (45.9\%) strongly agreed with P value 1.99. For the statement "time management during sessions is a great challenge for SLPs results showed that in male most of the participants $(35.7 \%)$ responded neutral with the statement while in female most participants (45.9\%) strongly agreed with $\mathrm{P}$ value 8.88 . For the statement, "colleague's collaboration at work place enhances treatment outcome" results showed that in male most of the participants $(35.7 \%)$ responded neutral with the statement while in female most participants $(60.7 \%)$ strongly agreed with $\mathrm{P}$ value 8.65 . For the statement, "more workload negatively affects outcomes of treatment" results showed that majority of males $(57.1 \%)$ and females $(50.8 \%)$ strongly agreed with $\mathrm{P}$ value 2.35 .

Table-2: Factors related to workload effecting the professional skills of speech therapist

\begin{tabular}{|c|c|c|c|c|c|c|c|c|c|c|}
\hline \multicolumn{5}{|c|}{ Male (14) } & \multicolumn{6}{|c|}{ Female (61) } \\
\hline 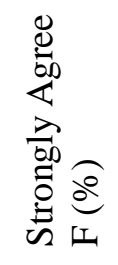 & 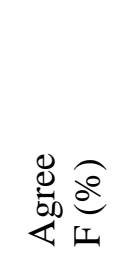 & $\underbrace{\overline{0}}_{\bar{Z}}$ & 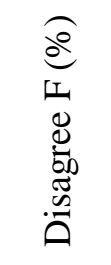 & 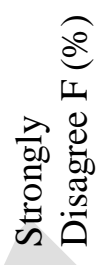 & 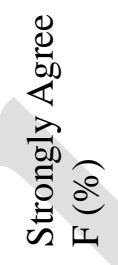 & 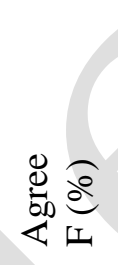 & $\underset{Z}{\stackrel{0}{0}} \underbrace{\widehat{Q}}_{I}$ & 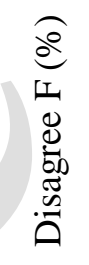 & 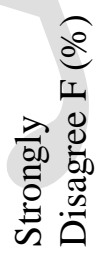 & $\begin{array}{l}\stackrel{\mathscr{D}}{\frac{\pi}{\sigma}} \\
\stackrel{2}{2}\end{array}$ \\
\hline \multicolumn{11}{|c|}{ No of Speech therapists are sufficient according to patients' ratio } \\
\hline $\begin{array}{c}4 \\
(28.6)\end{array}$ & $\begin{array}{c}5 \\
(35.7)\end{array}$ & $\begin{array}{c}1 \\
(7.1) \\
\end{array}$ & $\begin{array}{c}3 \\
(21.4)\end{array}$ & $\begin{array}{c}1 \\
(7.1)\end{array}$ & $\begin{array}{c}24 \\
(39.3)\end{array}$ & $\begin{array}{c}14 \\
(23)\end{array}$ & $\begin{array}{c}14 \\
(23)\end{array}$ & $\begin{array}{c}4 \\
(6.6) \\
\end{array}$ & $\begin{array}{c}5 \\
(8.2)\end{array}$ & 5.22 \\
\hline \multicolumn{11}{|c|}{ Facing work burnout due to excessive workload } \\
\hline $\begin{array}{c}5 \\
(35.7)\end{array}$ & $\begin{array}{c}4 \\
(28.6)\end{array}$ & $\begin{array}{c}4 \\
(28.6)\end{array}$ & $\begin{array}{c}1 \\
(7.1)\end{array}$ & $\begin{array}{c}0 \\
(0)\end{array}$ & $\begin{array}{c}28 \\
(45.9)\end{array}$ & $\begin{array}{c}18 \\
(29.5)\end{array}$ & $\begin{array}{c}9 \\
(14.8)\end{array}$ & $\begin{array}{c}4 \\
(6.6)\end{array}$ & $\begin{array}{c}2 \\
(3.3)\end{array}$ & 1.99 \\
\hline \multicolumn{11}{|c|}{ Insufficient time for therapy sessions due to extra workload } \\
\hline $\begin{array}{c}2 \\
(14.3) \\
\end{array}$ & $\begin{array}{c}4 \\
(28.6) \\
\end{array}$ & $\begin{array}{c}5 \\
(35.7) \\
\end{array}$ & $\begin{array}{c}3 \\
(21.4) \\
\end{array}$ & $\begin{array}{c}0 \\
(0) \\
\end{array}$ & $\begin{array}{c}27 \\
(44.3) \\
\end{array}$ & $\begin{array}{c}22 \\
(36.1) \\
\end{array}$ & $\begin{array}{c}8 \\
(13.1) \\
\end{array}$ & $\begin{array}{c}4 \\
(6.6) \\
\end{array}$ & $\begin{array}{c}0 \\
(0) \\
\end{array}$ & 8.88 \\
\hline \multicolumn{11}{|c|}{ Lack of collaboration team at work place for effective treatment outcome } \\
\hline $\begin{array}{c}4 \\
(28.6)\end{array}$ & $\begin{array}{c}4 \\
(28.6)\end{array}$ & $\begin{array}{c}5 \\
(35.7)\end{array}$ & $\begin{array}{c}1 \\
(7.1)\end{array}$ & $\begin{array}{c}0 \\
(0)\end{array}$ & $\begin{array}{c}37 \\
(60.7)\end{array}$ & $\begin{array}{c}11 \\
(18)\end{array}$ & $\begin{array}{c}12 \\
(19.7)\end{array}$ & $\begin{array}{c}0 \\
(0)\end{array}$ & $\begin{array}{c}1 \\
(1.6)\end{array}$ & 8.65 \\
\hline \multicolumn{11}{|c|}{ Extra workload negatively affects outcomes of treatment } \\
\hline $\begin{array}{c}8 \\
(57.1)\end{array}$ & $\begin{array}{c}2 \\
(14.3)\end{array}$ & $\begin{array}{c}2 \\
(14.3)\end{array}$ & $\begin{array}{c}2 \\
(14.3)\end{array}$ & $\begin{array}{c}0 \\
(0)\end{array}$ & $\begin{array}{c}31 \\
(50.8)\end{array}$ & $\begin{array}{c}16 \\
(26.2)\end{array}$ & $\begin{array}{c}11 \\
(18)\end{array}$ & $\begin{array}{c}3 \\
(4.9) \\
\end{array}$ & $\begin{array}{c}0 \\
(0)\end{array}$ & 2.35 \\
\hline
\end{tabular}

According to table-3 for the statement, "you have deep knowledge about the remedial strategies of different communication problems" results showed that majority of males (50\%) agreed with the statement while in females most participants (59\%) strongly agreed with $P$ value 6.12. For the statement, "your way of conversation and body language is easily understood by the patient" results showed that majority of males $(50 \%)$ and females $(52.5 \%)$ strongly agreed with $\mathrm{P}$ value 0.63 . For the statement, "you believe in teamwork in achieving therapy goals" results showed that majority of males $(57.1 \%)$ and females (63.9\%) strongly agreed with P value 1.48 . For the statement, "you maintain complete record of treatment of patients", results showed that majority of males $(42.9 \%)$ and females $(54.1 \%)$ strongly agreed with $\mathrm{P}$ value 2.04 . For the 
statement, "you can adjust treatment plans as needed by finding alternative ways to help your patients" results showed that majority of males (35.7\%) and females $(54.1 \%)$ strongly agreed with $\mathrm{P}$ value 2.98 . For the statement, "you are compassionate with emotionally demanding patients" results showed that majority of males $(64.3 \%)$ agreed with the statement while in females most participants (52.5\%) strongly agreed with P value 16.97. For the statement, "you listen to patient's symptoms and problems to decide on a course of treatment", results showed that majority of males (42.9\%) and females (60.7\%) strongly agreed with $\mathrm{P}$ value 5.34. For the statement, "you have lot of patience to deal with every kind of patients" results showed that majority of males $(35.7 \%)$ agreed with the statement while in females most participants (49.2\%) strongly agreed with P value 3.03 .

Table-3: Factors associated with professional knowledge

\begin{tabular}{|c|c|c|c|c|c|c|c|c|c|c|}
\hline \multicolumn{5}{|c|}{ Male (14) } & \multicolumn{6}{|c|}{ Female (61) } \\
\hline 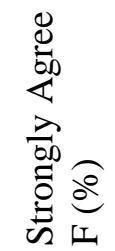 & $\underset{0}{0} \frac{0}{20}$ & 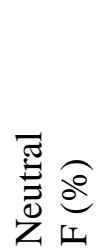 & 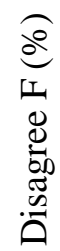 & 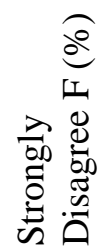 & 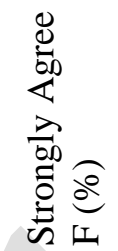 & 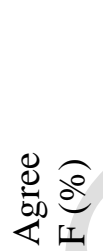 & 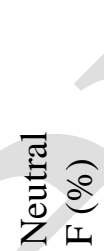 & 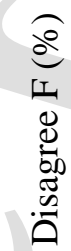 & 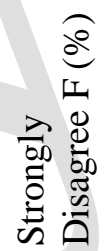 & 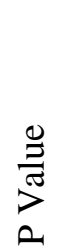 \\
\hline
\end{tabular}

You have deep knowledge about the remedial strategies of different communication problems

\begin{tabular}{|c|c|c|c|c|c|c|c|c|c|c|}
\hline 4 & 7 & 1 & 2 & 0 & 36 & 14 & 6 & 4 & 1 & 6 \\
$(28)$. & $(50)$ & $(7.1)$ & $(14.3)$ & $(0)$ & $(59)$ & $(23)$ & $(9.8)$ & $(6.6)$ & $(1.6)$ & \\
\hline
\end{tabular}

Your way of conversation and body language is easily understood by the patient

\begin{tabular}{|c|c|c|c|c|c|c|c|c|c|c|}
\hline 7 & 3 & 2 & 1 & 1 & 32 & 13 & 11 & 3 & 2 & 0 \\
$(50)$ & $(21.4)$ & $(14.3)$ & $(7.1)$ & $(7.1)$ & $(52.5)$ & $(21.3)$ & $(18)$ & $(4.9)$ & $(3.3)$ & 0.63 \\
\hline
\end{tabular}

You believe in teamwork in achieving therapy goals

\begin{tabular}{|c|c|c|c|c|c|c|c|c|c|c|}
\hline 8 & 4 & 1 & 1 & 0 & 39 & 12 & 6 & 2 & 2 & 1.48 \\
$(57.1)$ & $(28.6)$ & $(7.1)$ & $(7.1)$ & $(0)$ & $(63.9)$ & $(19.7)$ & $(9.8)$ & $(3.3)$ & $(3.3)$ & \\
\hline
\end{tabular}

You maintain complete record of treatment of patients

\begin{tabular}{|c|c|c|c|c|c|c|c|c|c|c|}
\hline 6 & 5 & 3 & 0 & 0 & 33 & 15 & 9 & 3 & 1 & 2.04 \\
$(42.9)$ & $(35.7)$ & $(21.4)$ & $(0)$ & $(0)$ & $(54.1)$ & $(24.6)$ & $(14.8)$ & $(4.9)$ & $(1.6)$ & \\
\hline
\end{tabular}

You can adjust treatment plans as needed by finding alternative ways to help your patients

\begin{tabular}{|c|c|c|c|c|c|c|c|c|c|c|}
\hline 5 & 4 & 3 & 1 & 1 & 33 & 15 & 7 & 5 & 1 & 2.98 \\
$(35.7)$ & $(28.6)$ & 21.4 & $(7.1)$ & $(7.1)$ & $(54.1)$ & $(24.6)$ & $(11.5)$ & $(8.2)$ & $(1.6)$ & \\
\hline
\end{tabular}

You are compassionate with emotionally demanding patients

\begin{tabular}{|c|c|c|c|c|c|c|c|c|c|c|}
\hline 1 & 9 & 1 & 1 & 2 & 32 & 20 & 4 & 5 & 0 & 16.97 \\
$(7.1)$ & $(64.3)$ & $(7.1)$ & $(7.1)$ & $(14.3)$ & $(52.5)$ & $(32.8)$ & $(6.6)$ & $(8.2)$ & $(0)$ & \\
\hline
\end{tabular}

You listen to patient's symptoms and problems to decide on a course of treatment

\begin{tabular}{|c|c|c|c|c|c|c|c|c|c|c|}
\hline 6 & 5 & 2 & 0 & 1 & 37 & 18 & 6 & 0 & 0 & 5.34 \\
$(42.9)$ & $(35.7)$ & $(14.3)$ & $(0)$ & $(7.1)$ & $(60.7)$ & $(29.5)$ & $(9.8)$ & $(0)$ & $(0)$ & \\
\hline \\
You have lot of patience to deal with every kind of patients \\
\hline \begin{tabular}{c}
\hline \\
$(28.6)$
\end{tabular} & 5 & 2 & 2 & 1 & 30 & 18 & 7 & 5 & 1 & 3.03 \\
\hline
\end{tabular}

According to table-4 for the statement "assessment tools according to the child's speech language problem are available at my work place", results showed that majority of males 
(42.9\%) and females (39.3\%) strongly agreed with P value 3.67. For the statement, "quality of the education and service delivery at my work place can be improved by using latest therapeutic and assessment tools" results showed that majority of males (35.7\%) agreed with the statement while in females most participants $(50.8 \%)$ strongly agreed with $\mathrm{P}$ value 6.30 . For the statement "at our workplace we use assistive devices as treatment approach to enhance the quality of treatment", results showed that majority of males (50\%) agreed with the statement while in females most participants (42.6\%) strongly agreed with $\mathrm{P}$ value 4.89 . For the statement, "standardized language assessment tools are available for assessment of the patients" results showed that majority of males $(42.9 \%)$ agreed with the statement while in females most participants $(44.3 \%)$ strongly agreed with $\mathrm{P}$ value 4.76.

Table-4: Factors associated with availability and use of assessment tools

\begin{tabular}{|c|c|c|c|c|c|c|c|c|c|c|}
\hline \multicolumn{5}{|c|}{ Male (14) } & \multicolumn{5}{|c|}{ Female (61) } & \\
\hline 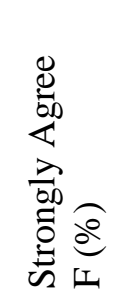 & 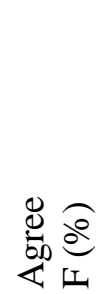 & $\underset{\mathrm{Z}}{\stackrel{\pi}{0}}$ & 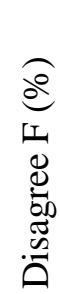 & 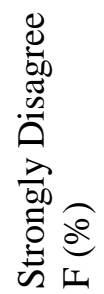 & 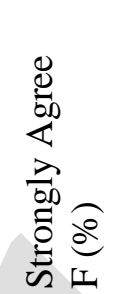 & 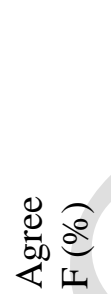 & 吾 & 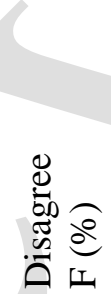 & 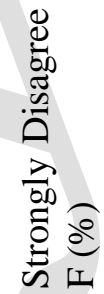 & 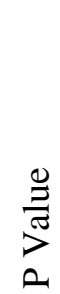 \\
\hline
\end{tabular}

Assessment tools according to the child's speech language problem are available at my work place

\begin{tabular}{|c|c|c|c|c|c|c|c|c|c|c|}
\hline 6 & 3 & 5 & 0 & 0 & 24 & 19 & 11 & 7 & 0 & 3.67 \\
$(42.9)$ & $(21.4)$ & $(35.7)$ & $(0)$ & $(0)$ & $(39.3)$. & $(31.1)$ & $(18)$ & $(11.5)$ & $(0)$ & \\
\hline
\end{tabular}

Quality of the education and service delivery at my work place can be improved by using latest therapeutic and assessment tools

\begin{tabular}{|c|c|c|c|c|c|c|c|c|c|c|}
\hline $\begin{array}{c}4 \\
(28.6) \\
\end{array}$ & $\begin{array}{c}5 \\
(35.7)\end{array}$ & $\begin{array}{c}3 \\
(21.4)\end{array}$ & $\begin{array}{c}2 \\
(14.3) \\
\end{array}$ & $\begin{array}{c}0 \\
(0)\end{array}$ & $\begin{array}{c}31 \\
(50.8)\end{array}$ & $\begin{array}{c}18 \\
(29.5)\end{array}$ & $\begin{array}{c}10 \\
(16.4)\end{array}$ & $\begin{array}{c}1 \\
(1.6) \\
\end{array}$ & $\begin{array}{c}1 \\
(1.6) \\
\end{array}$ & 6.3 \\
\hline \multicolumn{11}{|c|}{ At our workplace we use assistive devices as treatment approach to enhance the quality of treatment } \\
\hline $\begin{array}{c}3 \\
(21.4) \\
\end{array}$ & $\begin{array}{c}7 \\
(50) \\
\end{array}$ & $\begin{array}{c}2 \\
(14.3) \\
\end{array}$ & $\begin{array}{c}2 \\
(14.3) \\
\end{array}$ & $\begin{array}{c}0 \\
(0) \\
\end{array}$ & $\begin{array}{c}26 \\
(42.6) \\
\end{array}$ & $\begin{array}{c}18 \\
(29.5)\end{array}$ & $\begin{array}{c}12 \\
(19.7)\end{array}$ & $\begin{array}{c}3 \\
(4.9) \\
\end{array}$ & $\begin{array}{c}2 \\
(3.3) \\
\end{array}$ & 4.89 \\
\hline \multicolumn{11}{|c|}{ Standardized Language assessment tools are available for assessment of the patients } \\
\hline $\begin{array}{c}3 \\
(21.4) \\
\end{array}$ & $\begin{array}{c}6 \\
(42.9) \\
\end{array}$ & $\begin{array}{c}3 \\
(21.4) \\
\end{array}$ & $\begin{array}{c}2 \\
(14.3) \\
\end{array}$ & $\begin{array}{c}0 \\
(0) \\
\end{array}$ & $\begin{array}{c}27 \\
(44.3) \\
\end{array}$ & $\begin{array}{c}22 \\
(36.1) \\
\end{array}$ & $\begin{array}{c}9 \\
(14.8) \\
\end{array}$ & $\begin{array}{c}2 \\
(3.3) \\
\end{array}$ & $\begin{array}{c}1 \\
(1.6) \\
\end{array}$ & 4.76 \\
\hline
\end{tabular}

Findings of this study show that majority $90.7 \%$ of the participants are 20-30 years old. Also, a good majority $81.3 \%$ male participants and $44.0 \%$ participants had MS qualification. A majority of $68.0 \%$ participants were having 1 to 3 years of work experience. The work setting of the participants were a majority $52 \%$ works in special education centres. A huge majority 98.7\% were 0-20 times attended conferences. A huge majority $96.0 \%$ were $0-20$ times attended workshops. A huge majority $96.0 \%$ were $0-20$ times attended seminar. According to research on special education centres environment are being asked to have deeper understandings of child development and early education issues; to provide richer professional and educational experiences for all children.

In the present study, availability of a speech therapists, equipment availability, workplace environment and sufficient financial resources is necessary. A 24.0 percent of the participant agreed and 45.3 percent strongly agreed that speech therapists are always available to offer 
their services. A 29.3 percent of them responded neutral, 20.0 percent of them agreed that equipment available at my workplace is sufficient for providing the therapy needed. A 20.0 percent of them responded neutral, 16.0 percent of them agreed that at my workplace speech therapists are given separate place to carry sessions. A 29.3 percent of them responded neutral, 22.7 percent of them agreed that there are sufficient financial resources to carry out day to day tasks of the special education centres.

In this study, professional knowledge is another factors affecting the professional skills of speech and language pathologists in special education centres. A 28.0 percent of them agreed that you have deep knowledge about the remedial strategies of different communication problems. A 21.3 percent of them agreed that the patient easily understands the way of conversation and body language, whereas 52.0 percent strongly agreed. A 62.7 percent were strongly agree that you believe in teamwork in achieving therapy goals. The findings of this study show that factors affecting professional skills. A 28.0 percent of them agreed that you pay complete focus on patients during clinical sessions, whereas 56.0 percent strongly agreed. A 32.0 percent of them agreed that you feel motivated in dealing with every type of patients, whereas 45.3 percent strongly agreed. A 22.7 percent of them agreed that you take proper consent from patients caretakers before starting treatment, whereas 62.7 percent strongly agreed. A 36.0 percent of them were agree that you believe in creative ideas of treatment rather than bookish one, whereas only 48.0 percent were strongly agree.

In this study. workload was another factor affecting the professional skills of speech and language pathologists in special education centres. A 25.3 percent of them agreed that the number of speech therapists are sufficient according to patient's ratio, whereas 37.3 percent strongly agreed. A 29.3 percent of them agreed that due to the excessive workload sometimes it is frustrating to take that many sessions, whereas 44.0 percent strongly agreed. A 34.7 percent of them agreed that time management during sessions is a great challenge for SLPs, whereas 38.7 percent strongly agreed.

\section{Conclusion}

Male and female speech-language pathologists differed greatly on factors affecting their professional abilities in special education, such as availability, professional experience, workload, and evaluation tools. Such comprehensive research are proposed in the future to improve the factors influencing the application of professional skills in special education centres. There is also a need to strengthen vaccination policies and their implementation across the world. Such comprehensive research are proposed in the future to improve the factors influencing speech and language pathologists' professional skills in special education centres. There is also a need to strengthen vaccination policies and their implementation across the world. The findings of this study include previously unexplored knowledge about the factors influencing the ability of special education centres to implement professional skills and fulfil their roles and responsibilities. This analysis, however, had limitations due to the nature of survey research, operationally specified scales, and the researcher's assumptions. As a result, more research is needed to see how current SLPs can influence or inform pre-service or inservice education. 


\section{References}

Aguilar, Y. (2021). Exploration of Speech Language Pathology from a social justice and Critical Race Theory perspective. California State University, San Marcos. https://scholarworks.calstate.edu/downloads/765376265

Ch, A. F., Babur, M. N., Rashid, S., \& Liaqat, M. (2021). Interprofessional collaboration among Speech Language Pathologists and Nurses in acute care in Pakistan. Pakistan Journal of Medical Sciences, 37(2). https://doi.org/10.12669/pjms.37.2.3545

Anderson, K. L., Balandin, S., \& Stancliffe, R. J. (2015). Alternative service delivery models for families with a new speech generating device: Perspectives of parents and therapists. International Journal of Speech-Language Pathology, 17(2), 185-195. https://doi.org/10.3109/17549507.2014.979876

Boyle, M. P. (2015). Relationships between psychosocial factors and quality of life for adults who stutter. American Journal of Speech Language Pathology, 24(1), 1-12. https://doi.org/10.1044/2014_AJSLP-14-0089

Brandel, J. (2020). SLP service delivery decisions: How are they made? Communication Disorders Quarterly, https://doi.org/10.1177/1525740120951185

1525740120951185.

Calle-Romero, P., Valverde-Galan, P., Robles-Bykbaev, Y., Barros-Pontón, M. E., CanizaresJarrin, L., Robles-Bykbaev, V., ... \& Orellana-Peralta, J. (2017). YOCASTA: A ludicinteractive system to support the detection of anxiety and lack of concentration in children with disabilities. In 2017 IEEE International Autumn Meeting on Power, Electronics and Computing (ROPEC) (pp. 1-6). https://ieeexplore.ieee.org/abstract/document/8261603/

Campbell, W. N., \& Douglas, N. F. (2017). Supporting evidence-based practice in speechlanguage pathology: A review of implementation strategies for promoting health professional behaviour change. Evidence-Based Communication Assessment and Intervention, 11(3-4), 72-81. https://doi.org/10.1080/17489539.2017.1370215

Ch, F., Babur, M. N., Rashid, S., \& Liaqat, M. (2021). Interprofessioal collaboration among Speech Language Pathologists and Nurses in acute care in Pakistan. Pakistan Journal of Medical Sciences, 37(2), 489-493. https://doi.org/10.12669/pjms.37.2.3545

Chu, S. Y., Khoong, E. S. Q., Ismail, F. N. M., Altaher, A. M., \& Razak, R. A. (2019). Speech language pathology in Malaysia: Perspectives and challenges. Perspectives of the ASHA Special Interest Groups, 4(5), 1162-1166. https://doi.org/10.1044/2019_PERS-SIG17-2019-0005

Davidson, C., O’Hare, A., Mactaggart, F., Green, J., Young, D., Gillberg, C., \& Minnis, H. (2015). Social relationship difficulties in autism and reactive attachment disorder: Improving diagnostic validity through structured assessment. Research in Developmental Disabilities, 40, 63-72. https://doi.org/10.1016/j.ridd.2015.01.007

Douglas, N. F., Squires, K., Hinckley, J., \& Nakano, E. V. (2019). Narratives of expert SpeechLanguage Pathologists: Defining clinical expertise and supporting knowledge transfer. Teaching and Learning in Communication Sciences and Disorders, 3(2), 120. https://doi.org/10.30707/TLCSD3.2Douglas

Durrani, N., \& Halai, A. (2018). Dynamics of gender justice, conflict and social cohesion: Analysing educational reforms in Pakistan. International Journal of Educational Development, 61, 27-39. https://doi.org/10.1016/j.ijedudev.2017.11.010

Glover, A., McCormack, J., \& Smith-Tamaray, M. (2015). Collaboration between teachers and speech and language therapists: Services for primary school children with speech, 
language and communication needs. Child Language Teaching and Therapy, 31(3), 363-382. https://doi.org/10.1177/0265659015603779

Hamid, N. A., \& Johari, M. K. A. (2021). Hubungan kebolehcapaian persekitaran fizikal kampus terhadap prestasi mahasiswa orang kelainan upaya di Universiti Tun Hussein Onn Malaysia: Relationship between campus physical environment accessibility to the performance of disabled students at Tun Huss. Research in Management of Technology and Business, 2(1), 510-522. https://publisher.uthm.edu.my/periodicals/index.php/rmtb/article/view/1933

Hegarty, N., Titterington, J., \& Taggart, L. (2021). A qualitative exploration of speechlanguage pathologists' intervention and intensity provision for children with phonological impairment. International Journal of Speech-Language Pathology, 23(2), 213-224. https://doi.org/10.1080/17549507.2020.1769728

Hill, K. (2017). Role of Speech Language Pathologists in Assistive Technology Assessments. In Assistive Technology Assessment handbook (pp. 301-324). CRC Press.

Kadyamusuma, M. (2016). Limitations to practicing as a bilingual Speech Language Pathologist in the United States. Journal of Speech Pathology and Therapy, 1(2), e103. https://doi.org/10.4172/jspt.1000e103

Law, J., Dennis, J. A., \& Charlton, J. J. (2017). Speech and language therapy interventions for children with primary speech and/or language disorders. The Cochrane Database of $\begin{array}{lll}\text { Systematic Reviews, 2017(1), 1-21. } & \end{array}$ https://www.ncbi.nlm.nih.gov/pmc/articles/PMC6464758/

Luterman, D. (2021). Counselling parents at the time of diagnosis: Moving toward clientcentreed practice. American Journal of Audiology, 30(1), 226-230. https://doi.org/10.1044/2020_AJA-20-00122

Lytton, K., Woolley, T., Rasalam, R., Gorton, S., \& Heggarty, P. (2019). Benefits of simulated general practice clinics in the preparation of medical students for primary healthcare. Education for Primary Care, 30(5), 275-281. https://doi.org/10.1080/14739879.2019.1623087

Mngo, Z. Y., \& Mngo, A. Y. (2018). Teachers' perceptions of inclusion in a pilot inclusive education program: Implications for instructional leadership. Education Research International, 2018(1), 1-13. https://doi.org/10.1155/2018/3524879

Noor, H., \& Raja, N. A. (2019). Speech Language Therapy in special schools of Punjab: A study of auditory profiles of children with hearing impairment. Journal of Inclusive Education, 3(1), 97-110. https://jie.aiou.edu.pk/wp-content/uploads/2019/11/7-HinaNoor.pdf

Parveen, M. (2015). Evaluation of Phonological Assessment Practices of children with suspected speech sound difficulties conducted by Speech-Language Pathologists in Pakistan. Journal Riphah College of Rehabilitation Sciences, 3(1), 36-44. https://doi.org/https://journal.riphah.edu.pk/index.php/jrcrs/article/view/376

Roof, D. J. (2015). Problems of common interest: The shaping of education in Pakistan, 19702014. Pakistan Journal of Commerce and Social Sciences (PJCSS), 9(1), 35-51. https://doi.org/10419/188181

Shafaroodi, N., Kamali, M., Parvizi, S., \& Hassani Mehraban, A. (2017). Occupational Therapists' Clinical Reasoning: A Qualitative Study. Iranian Rehabilitation Journal, 15(3), 277-286. https://doi.org/10.29252/nrip.irj.15.3.277

Shahin, M., Ahmed, B., Parnandi, A., Karappa, V., McKechnie, J., Ballard, K. J., \& GutierrezOsuna, R. (2015). Tabby talks: An automated tool for the assessment of childhood 
apraxia of speech. Speech Communication, 70, 49-64. https://doi.org/10.1016/j.specom.2015.04.002

Short, L., Rea, T., Houston, B., Scott, S., \& Forducey, P. (2016). Positive outcomes for speech telepractice as evidence for reimbursement policy change. Perspectives of the ASHA Special Interest Groups, 1(18), 3-11. https://doi.org/10.1044/persp1.SIG18.3

Swan, K., Hopper, M., Wenke, R., Jackson, C., Till, T., \& Conway, E. (2018). Speech-language pathologist interventions for communication in moderate-severe dementia: A systematic review. American Journal of Speech Language Pathology, 27(2), 836-852. https://doi.org/10.1044/2017_AJSLP-17-0043

Thompson, C. (2019). Job satisfaction among school based Speech Language Pathologists [Ed.D., University of Houston]. ProQuest Dissertations \& Thesis Global. https://www.proquest.com/dissertations-theses/job-satisfaction-among-schoolbased-speech/docview/2471024506/se-2?accountid=135034

Volkmer, A., Spector, A., Warren, J. D., \& Beeke, S. (2020). Speech and language therapy for primary progressive aphasia: Referral patterns and barriers to service provision across the UK. Dementia, 19(5), 1349-1363. https://doi.org/10.1177/1471301218797240

Walsh, G. (2018). Biopharmaceutical benchmarks 2018. Nature Biotechnology, 36(12), 11361145. https://doi.org/doi:10.1038/nbt.4305

Weiss, A. L., \& Rohland, P. (2015). Implementing a Communication Coaching Program for students with Autism Spectrum Disorders in postsecondary education. Topics in Language Disorders, 35(4), 345-361. https://journals.lww.com/topicsinlanguagedisorders/Fulltext/2015/10000/Implement ing_a_Communication_Coaching_Program_for.6.aspx

Wilson, L., McNeill, B., \& Gillon, G. T. (2015). The knowledge and perceptions of prospective teachers and speech language therapists in collaborative language and literacy instruction. Child Language Teaching and Therapy, 31(3), 347-362. https://doi.org/10.1177/0265659015585374

Zerbo, O., Massolo, M. L., Qian, Y., \& Croen, L. A. (2015). A study of physician knowledge and experience with Autism in adults in a large Integrated Healthcare System. Journal of Autism and Developmental Disorders, 45(12), 4002-4014. https://doi.org/10.1007/s10803-015-2579-2 